\title{
Caracterização de matérias primas para produção de biodiesel
}

\author{
Giacomin, I. J. F. ; Santos, K. C. ${ }^{1}$; de Souza, K. M. ${ }^{1}$; Barañano, A. G ${ }^{2 *}$ \\ 1 Graduação em Engenharia Química, Universidade Federal do Espírito Santo, Alegre, ES, Brasil. \\ 2 Programa de Pós-Graduação em Engenharia Química, Curso de Graduação em Engenharia Química. \\ * e-mail: audrei@pq.cnpq.br \\ Departamento de Engenharia Rural, CCAE, Universidade Federal do Espírito Santo - UFES, Alegre, ES, Brasil
}

\begin{abstract}
Resumo
Segundo a Agência Nacional do Petróleo (ANP), o Brasil encontra-se entre os maiores produtores e consumidores de biodiesel do mundo, com uma produção anual de 2,9 bilhões de litros (2013) e uma capacidade instalada para cerca de 7,9 bilhões de litros. É um combustível renovável, utilizado em motores a diesel, e sua formação ocorre através da reação de transesterificação entre o óleo, álcool e catalisador. Neste trabalho foi analisado quatro amostras de óleo residual de fritura coletada em diferentes locais. Os parâmetros de densidade, índice de saponificação, umidade e viscosidade foram testados nas amostras. A densidade e índice de saponificação foram comparados com os parâmetros de óleo segundo a ANVISA, sendo que a densidade atendeu a especificações, diferente do índice de saponificação que apresentou resultados abaixo do esperado. De acordo com Barros, Wust e Meier (2008) o índice de umidade deve ser inferior a 0,5\%, sendo assim nossos dados foram satisfatórios. Além disso, observou-se que a viscosidade do óleo de soja utilizado em frituras é maior que a viscosidade do óleo de soja in natura, o que pode ser explicado pela formação de polímeros durante o processo de degradação.
\end{abstract}

Palavras chaves: Óleo de fritura, Transesterificação, Biodiesel.

\begin{abstract}
According to the National Petroleum Agency (ANP), Brazil is among the largest producers and world consumers of biodiesel, with an annual production of 2.9 billion liters (2013) and an installed capacity about 7.9 billion liters. It is a renewable fuel used in diesel engines, and its formation occurs through the transesterification reaction between the oil, alcohol and catalyst. In this study we analyzed samples from four residual oil frying collected at different sites. The density parameters, saponification index, humidity and viscosity were tested on the samples. The density and saponification value was compared with the oil parameters according to ANVISA, wherein the density met specifications, different from the saponification index that results presented below expectations. According to Barros, Wust and Meier (2008), the moisture content must be less than $0.5 \%$, thus our data were satisfactory. Furthermore, it was observed that the viscosity of the soybean oil used for frying is greater than the viscosity of soybean oil in nature, which can be explained by the formation of polymers during the degradation process.
\end{abstract}

Keywords: frying oil, transesterification, Biodiesel.

\section{Introdução}

O emprego de insumos renováveis, que substituem total ou parcialmente os combustíveis de origem fóssil como o petróleo, tem sido incentivado devido ao progressivo aumento da demanda por fontes de energia, pelas mudanças climáticas geradas e pelo esgotamento de reservas de petróleo de fácil extração (LOPES et al., 2013).

O biodiesel é um exemplo de combustível renovável e, de acordo com ANP (Agência Nacional do petróleo, gás natural e biocombustíveis), pode ser definido como "um combustível para motores a combustão interna com ignição por compressão, renovável e biodegradável, derivado de óleos vegetais ou de gorduras animais, que possa substituir parcial ou totalmente o óleo diesel de origem fóssil" (ANP, 2016). Além disso, quimicamente pode ser definido como uma mistura de ésteres alquílicos de ácidos graxos de cadeia longa derivados de óleos vegetais como o óleo de mamona, soja, girassol, como também de gorduras animais (DINELLI, et al., 2007).

O Brasil encontra-se entre os maiores produtores e consumidores de biodiesel do mundo, com uma produção anual de 2,9 bilhões de litros, em 2013, e uma capacidade instalada para cerca de 7,9 bilhões de litros (ANP, 2016). Em 2014, por meio da lei 13.033, estabeleceu-se a mistura obrigatória de $7 \%$ de biodiesel ao óleo diesel, contudo em 2016 esta mesma 
lei sofreu alterações e a adição obrigatória ocorrerá de forma gradativa até atingir os 10\%. A contínua elevação do percentual de adição de biodiesel ao diesel demonstra o sucesso do Programa Nacional de Produção de Biodiesel e uso do Biodiesel (ANP, 2016).

Este combustível pode ser utilizado em motores do ciclo diesel, puro ou como aditivo ao diesel de petróleo. Por ser um combustível renovável, apresenta uma série de vantagens ambientais, quando comparado com diesel de petróleo, como: é isento de enxofre, de compostos aromáticos, possui baixa emissão de monóxido de carbono e particulados (BRANDÃO, et al., 2006). Embora o biodiesel, forneça uma quantidade de energia menor que o diesel de petróleo, cerca de 10\%, seu desempenho no motor é praticamente o mesmo no que diz respeito ao torque e a potência. O biodiesel proporciona maior lubricidade que o diesel mineral pelo fato de ser mais viscoso, o que gera menor desgaste das partes móveis do motor (LÔBO, 2009).

A reação de transesterificação é, atualmente, o método mais utilizado para a produção de biodiesel, pois as características físico-químicas do produto obtido são semelhantes às características do óleo diesel (DINELLI, et al., 2007). A transesterificação consiste em uma reação orgânica, pela qual um triglicerídeo, presente nos óleos e gorduras, e um mono álcool de cadeia curta, geralmente metanol ou etanol, na presença de um catalisador (ácido ou base) reagem produzindo uma mistura de ésteres alquílicos de ácidos graxos (biodiesel) e glicerol (RINALDI, et al., 2006).

Para a produção do biodiesel, todos os óleos vegetais, enquadrados na categoria de óleos fixos ou triglicerídeos, podem ser utilizados. Além deles, gorduras animais e óleo de fritura usado também podem ser utilizados. Assim sendo, as seguintes espécies vegetais podem constituir matéria prima para a produção de biodiesel: grão de amendoim, polpa do dendê, amêndoa do coco de dendê, amêndoa do coco da praia, caroço de algodão, amêndoa do coco de babaçu, semente de girassol, baga de mamona, entre outros (UPB, 2016).

Utilizar óleo vegetal diretamente em motores do ciclo diesel causa problemas, uma vez que a viscosidade do óleo é alta, em comparação ao biodiesel, o que gera a degradação da pulverização do cilindro, reduzindo a eficiência da atomização, promovendo a contaminação do óleo lubrificante e a produção de fumaça preta. Com este combustível o motor funciona, no entanto, pode apresentar problemas ao longo do período de uso, comprometendo o seu desempenho (UPB, 2016).

Os óleos vegetais usados em frituras também podem ser utilizados para obtenção do biocombustível, o que proporciona a reciclagem do resíduo. Desse modo, a poluição gerada pelo descarte do óleo é reduzida, além de reduzir o custo da matéria prima para a produção do biodiesel. O produto obtido a partir desta matéria prima é comparável ao biodiesel produzido de óleo refinado (Geris, et al., 2007).

Por tudo isso, entende-se a importância da utilização do óleo de fritura como matéria prima para a produção de biocombustível. O presente trabalho tem como objetivo realizar a análise de quatro amostras de óleo de fritura usado de origens distintas, e observar suas diferenças físico-químicas. Sendo tais parâmetros, de grande relevância no processo de produção de biodiesel.

\section{Materiais e métodos}

Neste trabalho realizou-se a caracterização de quatro amostras de óleos residuais, com o objetivo de avaliar diferenças físico-químicas entre elas. Todas as amostras coletadas são óleos residuais de fritura, sendo que a primeira amostra foi recolhida no restaurante universitário do Campus de Alegre/UFES, a segunda em outro restaurante na mesma cidade e outras duas, recolhidas nas residências de dois alunos participantes do projeto.

Realizaram-se quatro tipos de análises: densidade, umidade, viscosidade e índice de saponificação.

Para a análise de densidade, utilizou-se densímetro digital Anton Paar DMA 4200, as densidades foram medidas a temperatura de $25^{\circ} \mathrm{C}$. A análise de umidade foi realizada com uma balança determinadora de umidade MOC63U. Para a viscosidade utilizou-se o viscosímetro digital Marte MVD-20.

Para a determinação do índice de saponificação, primeiramente adicionou-se em um erlemneyer de 250 $\mathrm{mL}$, uma alíquota de aproximadamente $2 \mathrm{~g}$ de óleo. Em seguida, adicionou-se $25 \mathrm{~mL}$ de solução alcoólica de hidróxido de potássio, com auxílio de uma bureta. A solução permaneceu à $40^{\circ} \mathrm{C}$ em banho-maria, durante 30 minutos. Posteriormente adicionou-se indicador fenolftaleína e titulou-se a quente com ácido clorídrico $0,5 \mathrm{M}$ até desaparecer por completo a coloração rósea. Paralelamente efetuou-se a titulação do branco, com as mesmas condições, mas sem a presença do óleo. $\mathrm{O}$ valor do índice de saponificação foi calculado de acordo com a equação (1).

$$
\text { I. } S=\frac{(\mathrm{V}-\mathrm{v}) * 28}{\mathrm{P}}
$$

Onde:

$\mathrm{V}=$ Volume de $\mathrm{HCL}$ 0,5M para titulação do branco $(\mathrm{mL})$;

v = Volume de HCL 0,5M para titular a amostra $(\mathrm{mL})$;

$\mathrm{P}=$ Massa da amostra $(\mathrm{g})$.

Para a viscosidade utilizou-se o erro do aparelho fornecido pelo fabricante $(0,005)$. 
A densidade, umidade e índice de saponificação foram feitas em triplicatas, pois é o recomendado para que haja um equilíbrio entre a precisão dos dados e o trabalho (PASSARI, et al., 2011). Para estes parâmetros foi calculado primeiramente o desvio padrão pela equação (2), e para 95\% de confiança dos dados, multiplicou-se o desvio padrão por dois para encontrar o erro experimental de cada parâmetro.

$$
S=\sqrt{\frac{\sum_{i=1}^{n}\left(x_{i}-\bar{x}\right)}{n-1}}
$$

Onde:

$\mathrm{n}$ = número de amostras;

$x_{i}=$ valor real da amostra;

$\bar{x}=$ média dos valores.

\section{Resultados e discussões}

Os resultados das análises estão reunidos na Tabela 1, de onde se pode observar que a origem do óleo influenciou nas características apresentadas. As diferenças observadas nas medidas estão relacionados com a maneira que o óleo foi utilizado, com o tempo de exposição à altas temperaturas e à quantidade de vezes que foi reutilizado, sendo visualmente perceptível pela coloração, na qual, óleos mais escuros indicam que foram mais utilizados. (DIB, 2010).

Tabela 1. Análises físico-químicas das diferentes amostras de óleo residual

\begin{tabular}{ccccc}
\hline DESCRIÇÃO & Amostra & Amostra & Amostra & Amostra \\
& $\mathbf{1}$ & $\mathbf{2}$ & $\mathbf{3}$ & $\mathbf{4}$ \\
\hline Densidade & $0,916 \pm$ & $0,919 \pm$ & $0,913 \pm$ & $0,917 \pm$ \\
(g/cm $^{3}$ ) & 0,001 & 0,000 & 0,001 & 0,000 \\
Saponificação & $156,301 \pm$ & $168,371 \pm$ & $140,494 \pm$ & $166,224 \pm$ \\
(mL/g KOH) & 13,095 & 10,077 & 32,815 & 9,319 \\
Umidade & $0,517 \pm$ & $1,020 \pm$ & $0,330 \pm$ & $0,387 \pm$ \\
(\%) & 0,064 & 0,111 & 0,028 & 0,011 \\
Viscosidade & $38,7 \pm$ & $38,6 \pm$ & $37,8 \pm$ & $50,3 \pm$ \\
(kg.m-1.s-1) & 0,005 & 0,005 & 0,005 & 0,005 \\
\hline
\end{tabular}

De acordo com a ANVISA (1999), o valor da densidade para o óleo de soja limpo, na temperatura de $25^{\circ} \mathrm{C}$, é de 0,916 a $0,922 \mathrm{~g} / \mathrm{cm}^{3}$. Dos resultados obtidos, apenas a densidade de amostra 3 não se encontra na faixa determinada pela ANVISA, no entanto não há um distanciamento considerável do valor ideal. Com isso, pode-se concluir que o fato do óleo ter sido utilizado para fritura não resultou em uma mudança considerável no parâmetro densidade.

O índice de saponificação do óleo de soja deve estar na faixa de 189 a 195. A análise deste parâmetro é importante, pois caso o óleo esteja fora dessa faixa, ocorrerá um aumento na emulsificação entre os ésteres e o glicerol, ou seja, entre o biodiesel e a glicerina ocasionando maior dificuldade na etapa de separação de fases (ANVISA, 1999). Assim os valores encontrados do índice de saponificação ficaram abaixo dos valores estabelecidos pela legislação brasileira.
Óleos recém refinados apresentam um teor de umidade inferior a $0,5 \%$, de acordo com Barros, Wust e Meier (2008). Para a produção de biodiesel, o teor de umidade do óleo deve ser o menor possível, pois a umidade acima de $0,5 \%$ provoca a hidrólise de triglicerídeos, o que proporciona o aumento do teor de acidez, formação de sabão e diminuição no rendimento das reações. A maioria das amostras apresentaram valores de umidade próximos e/ou menores a 0,5\%, o que demonstra que mesmo após o processo de fritura o aumento da umidade não impossibilita a utilização desses óleos para a reação de transesterificação. No entanto, a amostra 2 apresentou um valor de umidade muito acima do ideal, sendo explicado pelo fato de que a análise de umidade desta amostra foi realizada três meses após a coleta, logo a exposição deste óleo à atmosfera elevou o teor de umidade presente no mesmo.

Observou-se, pela viscosidade, que não houve alterações importantes entre algumas amostras. Já a viscosidade da amostra 4 teve valor maior do que as demais, o que pode ser explicado em função da viscosidade aumentar com a diminuição da temperatura e essa medida foi feita à $24,4^{\circ} \mathrm{C}$. O objetivo da reação de transesterificação é a redução da viscosidade dos óleos vegetais e gorduras a valores próximos a viscosidade do diesel, pois a alta viscosidade dos óleos in natura dificulta a utilização do mesmo como combustível.

De acordo com INOUE, et al (2004), a viscosidade do óleo de soja é de $0,003094 \mathrm{~kg} \cdot \mathrm{m}^{-1} \cdot \mathrm{s}^{-1}$. Observou-se, pela tabela 1, que a viscosidade do óleo de soja utilizado em frituras é maior que a viscosidade do óleo de soja in natura. Isso pode ser explicado pela produção de polímeros durante o processo de fritura. De acordo com Moraes (2011), esses polímeros são formados a partir do processo de aquecimento dos óleos e gorduras na presença de oxigênio do ar, o qual promove a sua oxidação térmica, gerando compostos radicalares instáveis. Além disso, a aumento da viscosidade também é causado pela formação de subprodutos lipídicos, como os monômeros cíclicos de ácidos graxos, que é favorecida pelas altas temperaturas atingidas no processo de fritura.

\section{Conclusão}

Óleos vegetais, quando submetidos à elevação de temperatura, têm suas características alteradas, podendo variar em grande proporção de acordo com a origem em virtude da forma de utilização e armazenamento. Isto resulta no distanciamento das condições ideais para o processo de obtenção de biodiesel, e assim pode ser indicado um pré-tratamento para corrigir algumas dessas características físicoquímicas. 


\section{Agradecimentos}

Os autores deste trabalho agradecem à FAPES pelo apoio financeiro ao projeto "Produção de biodiesel a partir de óleo de fritura" (EDITAL FAPES Nº14/2014PROGRAMA DE INICIAÇÃO CIENTÍFICA JÚNIOR). Agradecem, ainda, à UFES pela infraestrutura utilizada pelos alunos durante a realização deste trabalho.

\section{Referências}

ANP - Agência Nacional do Petróleo. Disponível em: <http://www.anp.gov.br/?pg=73292\&m=\&t1=\&t2=\&t3=\& $\mathrm{t} 4=\& a r=\& p s=\& 1473271624604>$. Acesso em: $17 \mathrm{de}$ Setembro de 2016.

DINELLI, L. R.; SALVATIERRA, C. R.; PEIXINHO, R. T.; SENE, J. J.; CASTILHO L. N. P. 2007. Produção de Biodiesel: Um experimento em Sala de Aula. Ciência e cultura. Vol. 2, No. 2. 63-67.

BRANDÃO, K. S. R.; SILVA, F. C.; NASCIMENTO, U. M., SOUZA; CONCEIÇÃO, M. M.; Moura, K. R. M.Produção de Biodiesel por Transesterificação do Óleo de Soja com Misturas de Metanol-Etanol. P. 142146. João Pessoa, 2006.

LÔBO, I. P.; FERREIRA S. L. C. Biodiesel: parâmetros de qualidade e métodos analíticos. Quim. Nova, Vol. 32, No. 6, 1596-1608, 2009.

LOPES, S.J.M.; DA SILVA, E.P.; MARTINS, V.L.; DE SOUZA, M. Produção e análise de alguns parâmetros físico-químicos do biodiesel obtido do óleo de cupuaçu. $6^{\circ}$ simpósio nacional de biocombustíveis. Canoas, 2013.

UPB - União dos Produtores de Bioenergia. Disponível em:<http://www.udop.com.br/download/estatistica/biodi esel/10jan12_oleo_vegetal.pdf $>$. Acessado em: 17 de Setembro de 2016.

GERIS, R., DOS SANTOS, N. A. C., AMARAL, B. A., MAIA, I. DE S., CASTRO, V. D.\& CARVALHO, J. R. M. 2007. Biodiesel de Soja - Reação de Transesterificação para Aulas Práticas de Química Orgânica. Química Nova. Vol. 30, No. 5, 1369-1373.

INOUE, G. H.; LACERDA FILHO, A. F.; VIEIRA, L. B.; DE RESENDE, R. C. Variação da viscosidade cinemática de óleos vegetais brutos em função da temperatura. II Congresso Brasileiro de Plantas Oleaginosas, Óleos, Gorduras e Biodiesel. Universidade Federal de Lavras, 2004.

ANVISA, Agência Nacional de Vigilância Sanitária. Resolução RDC no 482, de 23 de setembro de 1999. D.O.U. - Diário Oficial da União; Poder Executivo, de 13 de outubro de 1999.

MORAIS, V. S. de. Avaliação da qualidade do biodiesel em função da matéria-prima utilizada: óleos residuais de fritura de diferentes tipos e fontes. Dissertação de
Mestrado em Química e Recursos Naturais Universidade Federal do Espírito Santo. Vitória, 2011.

DIB, H. F. Produção de biodiesel a partir de óleo residual reciclado e realização de testes comparativos com outros tipos de biodiesel e proporções de em um moto-gerador. Dissertação de mestrado em Engenharia Mecânica. Universidade Estadual Paulista, 2010.

PASSARI, L. M. Z. G; SOARES, P. K.; BRUNS, R. E. Estatística aplicada à química: dez dúvidas comuns. Quim. Nova, Vol. 34, No. 5, 888-892, 2011. 